\title{
Erratum to: A low-cost visual occlusion device
}

\author{
Sangcheol Lee • Sekee Kil • Taewhan Kim
}

Published online: 8 March 2014

(C) Psychonomic Society, Inc. 2014

Erratum to: Behav Res

DOI 10.3758/s13428-013-0428-9

The correct spelling of the first author is Sangcheol Lee.

The online version of the original article can be found at http://dx.doi.org/ 10.3758/s13428-013-0428-9.

S. Lee $(\bowtie) \cdot$ S. Kil $\cdot$ T. Kim

Korea Institute of Sport Science, Seoul, South Korea

e-mail:k2001sc@hanmail.net 